\title{
Biomaterials Involved in Frontal Area Restorations in Pediatric Dentistry
}

\author{
ANA PETCU, CARMEN SAVIN*, ADRIANA BALAN, EUGENIU MIHALAS*, LAURA MARIA GAVRILA, CARINA BALCOS, \\ MAGDA ECATERINA ANTOHE \\ Grigore T. Popa University of Medicine and Pharmacy lasi, Faculty of Dental Medecine, 16 Universitatii Str., 700115, Iasi, Romania
}

\begin{abstract}
Aesthetics in dentistry have truly begun their role in the mid-twentieth century through attempts to perform orthodontic prosthetic restorations in the spirit of dentogenia, thereby making it as natural as possible. The aim of the study is represented by the identification of corellative aspects bethween the incidence of frontal edentation at young patients and the condition for a specific therapy. For the clinical study, 120 young patients were placed under observation, patients which showed up at the Paediatric Dentistry Clinic and private dental practices during the time interval 2016-2018, diagnosed with multiple and various pathologies in frontal area. The patients' age was between 5 and $20+$ years, $34.21 \%$ having the age between 15 and 20 years, $60.53 \%$ with age past 20 years, age intervals which, although anchored within the young dentistry framework, present different morphological and functional features, which lay at the foundations of the selection or exclusion of one or the other of the solution therapy solutions of the partial toothless. Regarding the prevention of the therapeutic solutions within the studied group we observe the weight of the temporary solutions for the childhood duration, followed by restorations with composed materials, significant statistical percentages belonging to the fixed restorations with the metal and ceramic crowns, the lowest percentage belonging to the ceramic-type restorations with zirconium or fully ceramic ones, choice dictated by the social and economic criteria, at the patients in which the grow th process stagnated, essential elements of the patient's final behaviour with regard to the body scheme reception. Toothless architecture will lay at the basis of the prosthetic rehabilitation in full accordance with the factorial accumulation, embracing valences of high exigency at the teenager's age, the frontal toothless being perceived as an amputation, forcing the teenager in isolation. In full accordance to the age and the particular clinical situation with regard to the successful esthetical restoration, the preparation and non-preparation actual techniques for the integrated ceramics constitute a selection option.
\end{abstract}

Keywords: frontal edentulous, biometarials, esthetic restaurations

In the past decades, the treatment of the front edentation has known major changes in multiple causes, including increasing the length of arched tooth maintenance and introducing new techniques, materials and methods. The increasing frequency of partial edentation in young people, especially due to dental caries and complications, as well as other illnesses, requires a closer analysis and a reconsideration of the therapeutic attitude that is carefully adapted and nuanced. Thus, the chain of dentistry of the age groups starting with infantile dentistry, continues with the juventostomatology, the adult dentistry itself and goes with the gerontostomatology [1-3].

The closer approach of teenagers with dental conditions has led to the conclusion that this pathology sometimes differs from the entities described in the adult or the child. This age group is the most dynamic, the most capable, but also the most subjected to change and tension.

The frontal edentation in the child has a profound impact on the subsequentmorpho-functional development of the stomatognat system, the essential causes of edentosis occurring during this time being associated with traumatic or apparent causes.

The age of adolescence is characterized by an intensification of etiopathogenic mechanisms of caryopathy and periodontal disease, and from the gnatological point of view through psycho-physiological reactions followed by bruxism, occluso-articular dysfunctions and neuromuscular imbalances $[4,5]$.

Children and adolescents often experience important dificulties linked with dental health problems.

These are due to cumulative factors: sometimes a limited skill to brush, postponement of dental control to the patient and/or his/her elderly until the occurrence of a nocturnal symptomatology, some particularities of disease characteristic of general disease or induced by its treatment and last but not least, the reticence of the practitioner regarding the clinical approach of this category of patients, usually motivated by the difficulties of collaboration.

The pathology of the frontal edentation of the child and adolescent is a complex problem, with profound impact on the dento-somato-facial harmony, raising the clinician's interest in an optimal therapeutic approach.

The emotional impact on the child is special, often he becomes introverted, forgets to smile, and it becomes difficult to integrate into everyday life.

The perception of attitudes related to the pathology of the child's and adolescent's edentation involves differences expressed both in the position of the principal and the medical factor.

The last years show a significant increase in the number of frontal edentations across the map, the variables being determined by a multitude of factors.

The consequences of the front edentation on the social integration of the young patient have a particularly high impact, impinging on his psychic behaviour. Therefore, partially removable prostheses (therapeutic solutions of choice in such cases) have sustained and will support improvements over time to alleviate the psychiatric disorders that arise from the alteration of body pattern [ 6 8].

The increasing frequency of partial editing in young people, due in particular to tooth decay and its complications, as well as other illnesses, requires a closer analysis and a reconsideration of the therapeutic attitude that is carefully adapted and nuanced.

*email: savin.carmen@gmail.com; emihalas@yahoo.com

REV.CHIM.(Bucharest) 69 No.121 $2018 \quad$ http://www.revistadechimie.ro 
The variety of clinical cases faced by the practitioner is a particularly important element in choosing the particularities of developing partial prosthetic constructions .In young patients, restorations will especially take into account the reproduction of primary morphology and aesthetic function. Young patients often have dental and occlusal disharmonies, which are still responsible for orthodontic, mainly fixed treatments.

The assessment of the incidence and prevalence of the frontal edentation correlated with its etiology in the child and adolescent is a pertinent starting point for the argumentation and diversification of the choice of the treatment solution dictated by a number of very important parameters regarding the general loco-regional and local aspects, odonto-periodontal, without eluding the biopsycho-social impact this clinic entity has on the child, getting dramatic accents in the body's perception of the body pattern by the adolescent $[9,10]$.

The necessity of hierarchizing therapeutic solutions to the very young patient is due to the failures that any predominantly therapeutic solution anchored in the mobile prosthetic area recommended to the adult patient can generate [11-13 ].

The exigencies that govern the frontedentulous therapy in the teenager and the young patient are anchored both in the aesthetics sphere, a pre-eminent requirement at this age stage, sometimes surpassing the desire for functionality, although this requirement is equally important. In order to materialize aesthetic valences, a careful selection of the therapeutic solution that combines both current biomaterials and minimally invasive techniques of preparation and preservation of the prosthetic field structures, a central place occupying implanto-prosthetic therapy, is required [14-16].

The purpose of the study is to establish the prevalence and incidence of the frontal edentation in the child and adolescent with the identification of its etiology and the prospects of restoring the affected morpho-functional parameters, anchored in the provisional or definitive solutions, according to the age and morpho-functional development of the patient. will determine the correlation between the particularities of the clinical cases in the partially frontal edentated patients and the therapeutic variant chosen, resulting in the therapeutic criteria and the principles governing the choice of the therapeutic solution of choice, in the context of the perceptual aspect of the edentation, a fundamental element dependent on a factorial cumulation.

\section{Experimental part}

From the field of methods of evaluation and monitoring of the degree of knowledge on certain subject categories of a topic with deep practical impact, the questionnaire method remains undeniable from the point of view of adressability and especially of interpreting the results offering a X-ray for the problem taken into account and especially for the solutions that can solve it.

The way of working was materialized by developing a questionnaire for children and adolescents in accordance with the cognitive level of the age, the results of which are corroborated with clinical examination data. For the clinical trial a representative number of patients was taken into account. The study lot consisted of a total of 320 patients who presented themselves in the Clinic of Pediatric Dentistry in 2016-2018, diagnosed with multiple pathologies and varied, of which the front edentation targeted 120 cases aged between 15 and 25 years.

\section{Results and discussions}

The collected data were processed using a programme dedicated to medical analysis and statistics.

We found a prevalence of female sex (fig. 1), which is the basis of the predominance of aesthetic characteristics in the future prosthetic restorations, correlated with the odonto - periodontal status and muco-bone, it is known that aesthetics is the essential requirementassociated with the female sex, at the same time the age range analyzed is the adequacy of these exigencies, essential aspects in the choice of the therapeutic solutions according to the type of edentation and the complications installed.

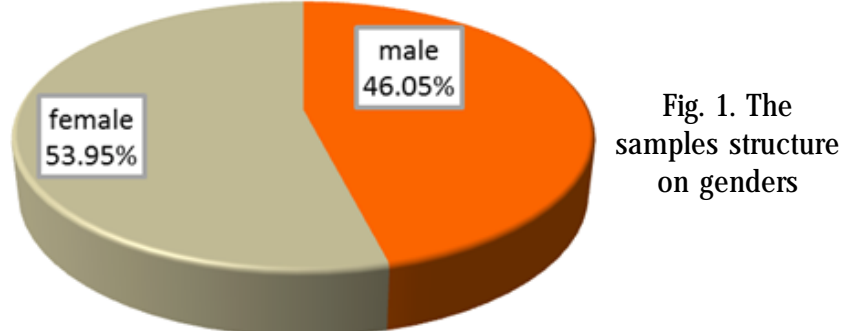

Regarding the prevalence of the solutions in the studied group we note the weight of the provisional solutions for childhood, followed by the restorations with composite materials, statistically significant percentages of fixed restorations by metal-ceramic crowns, the lowest percentage being the restorations of ceramic type on zirconium or whole ceramics, dictated choice the patient's stagnation of the growth process, essential elements of the patient's final behavior regarding the body's pattern (fig. 2).

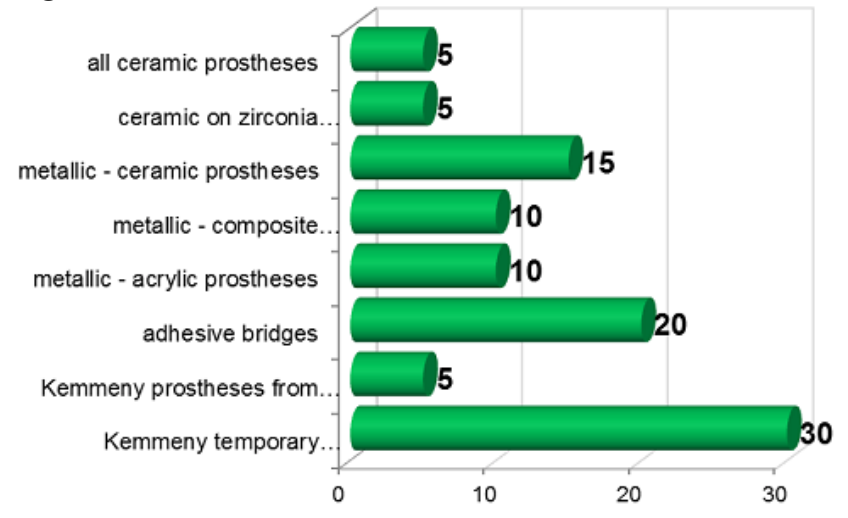

Fig. 2. Types of restaurations involved in frontal area rehabilitation at young patients

Patients who want an aesthetic treatment for the previous teeth are increasing in numbers. Consistent with this, several treatment options have been proposed to restore the aesthetic aspect of the teeth. For many years, the aesthetic correction of the most predictable and lasting anterior teeth has been achieved through total crown preparations, butthis is a method of invasion since itinvolves the removal of a significant amount of dental substance and adverse effects on the dental pulp or periodontal tissue may occur.

A great breakthrough in the ability to bond to enamel and dentin was achieved with the introduction of multistep adhesive systems, with the development of hybrid composite resins that allowed for more conservative restorative techniques.

Composite resin beads can be used to mask dental discolorations to correct non-aesthetic forms of teeth and their position. However, these restorations have the disadvantage of limited longevity, as the composite resin remains susceptible to colouring, wear and fracture of the edges, and over time the aesthetic results are reduced. 
Consequently, for a much more durable aesthetics, the ceramic facades have recently been introduced; glazed ceramic facades have been proposed to increase the resistance of previous restorations and superior aesthetics.

In the area of clinical forms of periodontitis that affect the frontal area physiognomy, we notice equal percentages of chronic gingivitis, hyperplasic gingivitis, profound, superficial marginal periodontitis without eluda occlusal trauma.

We also looked at the edentation classes of the patients in the study group. The most common situation was that of the first Kennedy class - found in $28 \%$ of cases, followed by Kennedy class II (20\%) and class III ( $20 \%$ of cases), a major proportion of the front edentation, $16 \%$ (4th grade) (fig. 3).

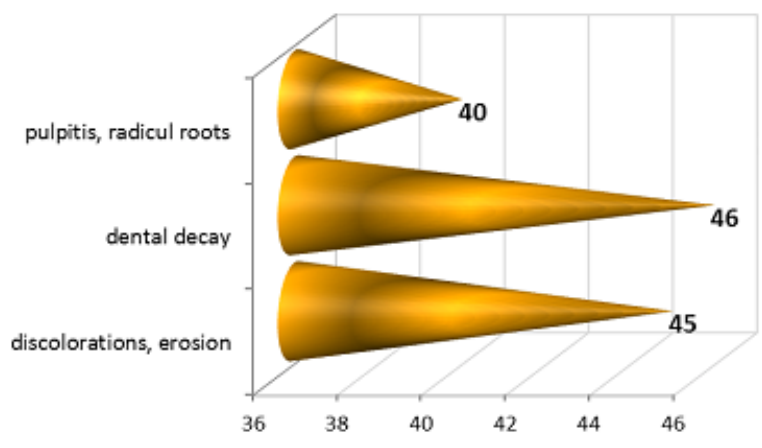

Fig. 3. The incidence Kennedy edentulous

With regard to the anatomic-clinical forms of coronary lesions of frontal teeth that require aesthetic revitalization, we notice the prevalence of dental caries, followed by different forms of abrasion and milliolysis, a small percentage of enamel and coronary cracks, as well as dental dysplasia, aspects that influence the final therapeutic decision (fig. 4).

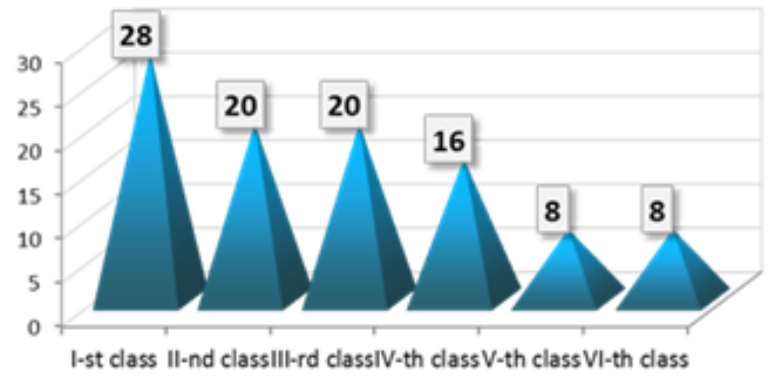

Fig. 4. Odontal Integrity and pathology

From the area of clinical forms of parodontopathies that affect the physiognomy of the frontal area, we notice equal percentages of chronic gingivitis, hyperplasic gingivitis, deep, superficial, periodontal periodontitis withoutocclusal trauma.

Nowadays, the society greatly emphasizes on the aesthetic aspect of the face, which is of particular importance for achieving normal relationships in a society as well as social integration.

The aesthetic aspect of the face is largely determined by the appearance of visible dental arches during speech and smile and the relationship of the dental units to the orofacial structures.

Achieving favourable social relationships relies heavily on the aesthetic aspect in general of the person concerned, and especially with regard to our profession as well.

Ceramic materials are particularly sensitive to traction stresses, and mechanical strength is strongly influenced by the presence of superficial defects and internal voids.
This phenomenon can be influenced by various factors such as marginal design and restoration thickness, residual processing stress, elasticity of restorative components, cement defects and the effects of the oral environment.

The package preparation type, combined with the type of restoration, is an essential element long-term therapeutic success. Florian Beuer suggested that the right threshold has a fracture resistance greater than the deep chamfer threshold and the chamfer edge.

Sadan et al [17] proposed that both types of finishing lines are considered to be appropriate to the tooth. However, Di Lorio et al [18] suggested that the right threshold could improve the biomechanical performance of a uni-dental crown restored with alumina. De Jager etal [19] found that for long-lasting restorations in the posterior region it is advisable to make a collar chamfer.

Cho L. [20] found that the fracture power of the chamfer threshold $(0.9,1.2 \mathrm{~mm})$ was greater than the $1.2 \mathrm{~mm}$ rounded straight margin. Potiket has suggested that a straight $1 \mathrm{~mm}$ threshold with a rounded inner line has power against good fracture for restored natural teeth with full ceramic crowns. Rammersberg found that a minimally invasive axial chamfer of $0.5 \mathrm{~mm}$ of the tooth has the highest stability for hind-metal crowns. The purpose of the current in vitro study was to compare fracture resistance under a cyclic load of zirconium restorations with the respective chamfer threshold, the deep chamfer.

The most used types of frontal area restorations in young patients are anchored in the metal-ceramic register, zirconium-ceramic ceramics and integral ceramics.

Representative for rehabilitation of the frontal area in young patients, we selected the case of a 23-years old woman with coronal odontal lesions at level 11, 21 and 22, prosthetic rehabilitation at level 11, 21, and ceramic restoration on zirconium support, aesthetic considerations were present in the development of the therapeutic plan, taking into account the shape of the face, the type of smilet, and the duperability of the central incisor shape on the face shape.

\section{Conclusions}

After this study we concluded that:

The prevalence of the group of patients diagnosed with frontal edentation in the analyzed area leads to the creation of an epidemiological model with profound impact in dental practice.

The etiology of the frontal edentation has an essential role in the anatomical-clinical form of the edentation, without eluding the impact on the bio-psycho-social dimension of this clinical entity.

Editing architecture will be the basis of prosthetic rehabilitation in full agreementwith factorial cumulation, dressing high-intensity valences in adolescence age, finite front edentation perceived as an amputation, condemning to teenage isolation.

\section{References}

1.VANHERLE, G., DECLERCK, D., Verh K Acad Geneeskd Belg, 65, no. 4, 2003, p. 233.

2.BANOCZY, J., MARTHALER, T.M., Fogorv. Sz., 97, no. 1, 2004, p. 3. 3.CAREY, C.M., J. Evid. Based. Dent. Pract., 14, 2014, p. 95.

4.ELKASSAS, D., ARAFA, A., J ournal of Dentistry, 42, 2014, p. 466. 5.LUCA, F.A., IOAN, C.A.M., SASU, C., LUCA, A.C., Revista de Cercetare si Interventie Socialã, 49, 2015, p. 80.

6.STOVELL, A.G., NEWTON,B.M., LYNCH, R.J ., Int. Dent. J., 63, no.2, 2013, p. 57. https://www.ncbi.nlm.nih.gov/pubmed/24283285

7.HIROSE, M., MURATA, Y., FUKUDA, A., FUJITA, Y., OTOMO, M., YAHATA, S., SAITOH, M., Pediatric Dental Journal, 25, no. 2, 2015, p. 45. 
8. SKUCHA-WAK, M., GIBAS, M., TANASIEWICZ, M., TWARDAWA, H., SZKLARSKI, T., Adv. Clin. Exp. Med., 24, no. 5, 2015, p. 891.

9.LENZI, T.L., CALVO, A.F., TEDESCO, T.K., RICCI, H.A., HEBLING, J., RAGGIO, D.P., BMC Oral Health., 11, no.15, p. 79.

10.TEN CATE, J.M., Caries Res., 49, no.1, 2015, p. 3.

11.CHEN, Z., CAO, S., WANG, H., LI, Y., KISHEN, A., DENG, X., YANG, X., WANG, Y., CONG, C., WANG, H., ZHANG, X., PLoS One., 10, no. 1, 2015, Article no. e0116553.

12.RYOU, H., NIU, L.-N., DAI, L., PUCCI, C.R., AROLA, D.D., PASHLEY, D.H., TAY, F.R., J. Dent. Res., 90, no. 9, 2011, p. 1122.

13..KOIKE, T., POLAN, M.A.A., IZUMIKAWA, M., SAITO, T., Biomed. Res. Int., 2014, 2014, Article no. 745139.

14.MANESH, S.K., DARLING, C.L., FRIED, D., Proc. SPIE Int. Soc. Opt. Eng., 1, 2009, p. 71620.
15. SHETTY, S., HEGDE, M.N., BOPANNA, T.P., J. Conserv. Dent., 17, no.1, 2014, p. 49.

16. LI, Q.L., NING, T.Y., CAO, Y., ZHANG, W., MEI, M.L., CHU, C.H. BMC Biotechnology, 14, 2014, p. 32.

17.SADAN, A., BLUTZ, M.B., LANG, B.,. Int. J. Periodontics Restorative Dent., 25, 2005, p. 213.

18. DI LORIO, D. MURMURA, G., ORSINI, G., SCARANO, A., CAPUTI, S., J. Contemp. Dent. Pract., 9, 2008 , p.8.

19. DE JAGER, N., PALLAV, P., FEILZER, A.J., Dent. Mater., 21, no. 3, 2005, p. 242.

20. CHO, L., CHOLI, J., YI, Y.J., PARK, C.K., J. Prothet. Dent, 91, 2004, p. 554.

$\overline{\text { Manuscript received: } 21.07 .2018}$ 